\title{
Natural history of gastroesophageal reflux in infancy: new data from a prospective cohort.
}

Marlene Curien- Chotard ( $\nabla$ mcurien@chu-besancon.fr)

Centre Hospitalier Regional Universitaire de Lille Pole de Biologie Pathologie Genetique https://orcid.org/0000-0002-3510-0242

\section{Prévost Jantchou}

Centre Hospitalier Universitaire Sainte-Justine

\section{Research article}

Keywords: Gastroesophageal reflux, gastroesophageal reflux disease, infancy, Infant Gastroesophageal Reflux Questionnaire Revised, I-GERQ-R, pediatric practice, regurgitation

Posted Date: December 24th, 2019

DOI: https://doi.org/10.21203/rs.2.19538/v1

License: (c) (i) This work is licensed under a Creative Commons Attribution 4.0 International License. Read Full License 


\section{Abstract}

Objective

Gastroesophageal reflux (GER) is common in infants. Gastroesophageal reflux disease (GERD) is defined as GER leading to troublesome symptoms that affect daily functioning and/or complications. This study aimed at determining the prevalence and progression of GER and GERD in a cohort of healthy term infants from birth to 12 months old.

\section{Methods}

We conducted a prospective cohort study including all full-term living neonates born at Besançon Teaching Hospital, France. Exclusion criteria were: congenital anomaly. Parents completed a clinical report form and the Infant Gastroesophageal Reflux Questionnaire Revised (I-GERQ-R) at 1, 3, 6, 10, and 12 months of age. GER was defined as score $\geq 1$ to the first question with I-GERQ-R score $<16$; and GERD as score $\geq 1$ to the first question with I-GERQ-R score $\geq 16$.Findings $157 / 347$ births were included ( 83 boys). The prevalence of regurgitation at least once a day was $45.7 \%$ overall. In total: $72 \%, 69 \%, 56 \%, 18 \%$ and $13 \%$ of infants regurgitated at least once a day at $1,3,6,10$, and 12 months of age, respectively. Physiological GER affected $53 \%, 59 \%, 51 \%, 16 \%$, and $12 \%$ of infants; GERD, $19 \%, 9 \%, 5 \%, 2 \%$, and $2 \%$, respectively. Two risk factors were identified: family history of GER and exposure to passive smoking. Treatment included dietary modification (14\%) and pharmacotherapy (5\%).

Conclusion

Physiological GER peaked at 3 months, GERD at 1 month. Most cases resolved on their own. Parents should be reassured/educated regarding symptoms, warning signs, and generally favorable prognosis. Pharmacologic agents are justified only for ascertained GERD. I-GERQ-R does not replace more invasive investigations to confirm diagnosis in selected cases.

\section{Background}

Gastroesophageal reflux (GER) is a common and normal physiological process in children whetever their age [1]. In 2009 both the North American Society for Pediatric Gastroenterology Hepatology, and Nutrition (NASPGHAN) and the European Society for Paediatric Gastroenterology, Hepatology and Nutrition (ESPGHAN) defined GER as the passage of gastric contents into the esophagus with or without regurgitation and vomiting [1]. GER is usually the consequence of an insufficiency of the lower esophageal sphincter tonus and other anatomical factor [2], GER can occur after meals several times a day, with little or no symptoms [1]. In 2018 gastroesophageal reflux disease (GERD) was redefined as a condition leading to troublesome symptoms that affect daily functioning and/or complications of GER [3]. 
The diagnosis of GER and GERD relies on clinical symptoms and signs (medical history and physical examination) but these are non-specific, particularly in infants [1]. Additional diagnostic investigations are led to qualify and quantify GERD and to rule out conditions other than GERD [3].

The prevalence of GER and GERD vary according to the population, the study design (cross-sectional or longitudinal), and the diagnostic criteria (visible symptoms vs. validated questionnaire). A French study estimated that $24.4 \%$ of infants ( $0-23$ months) had symptoms of GER and prevalence of GERD was $12.6 \%$ [4]. GER has been reported as a common condition until 3 months of age, with a reported peak in regurgitation at 4 months of age ( $67 \%$ of infants). At 6 months, $23 \%$ infants were symptomatic [5]. Another study published a peak in spitting/vomiting ("spilling") at 3-4 months of age (41\% of infants) [6]. Overall $12 \%$ children aged 1 to 12 months were diagnosed with infant regurgitation [7]. A prospective study of healthy infants from birth to 6 months in the USA, indicated a peak prevalence of regurgitations $\geq$ once/day of $83 \%$ at 4 months of age and of GERD $25 \%$ at 1 month of age, decreasing thereafter [8].

During the last years, the number of parents seeking pharmacological treatment for GER in our clinical practice, has been increasing with a corresponding increase in prescriptions of drugs such as proton pump inhibitors (PPIs) in infants [9-12].

The primary aim of our study was to determine the prevalence and the progression of GER and GERD in a cohort of infants from birth to one year of age in the eastern part of France. The secondary aims were to examine the pattern of drug prescription and to identify risk factors for GER and GERD in this cohort.

\section{Methods}

Study design: a prospective cohort study

\section{Participants:}

All infants born at term at Besançon Teaching Hospital, France, during the two months of study recruitment (October 2009-December 2009) were eligible for this study. The inclusion criteria were as follows: (1) Parents able to read and write French and (2) Familial residence at the same address without any plans to move for at least one year. The Exclusion criteria consisted of the following: (1) preterm birth, (2) Pierre Robin syndrome or other otolaryngological or digestive defects (diaphragmatic hernia, omphalocele and gastroschisis), (3) congenital heart disease, (4) neonatal neurological disorder, (5) other congenital malformations and (6) an intestinal surgery in the first three months of life.

Data collection: after informed consent, each family was asked to fill the Gastroesophageal Reflux Questionnaire Revised (I-GERQ-R) alongside with a case report form.

The I-GERQ was developed by Orenstein et al. [13-14] and Kleinman et al. [15] to assess the symptoms of GER and GERD in children. The I-GERQ-is a shorter version of the I-GERQ-R that was developed and validated in seven countries. 
The mother or the father completed five self-reported questionnaires at home, when the infant was 1, 3, 6 , 10 , and 12 months old. One postal mail reminder was sent to non-responders and those who still did not respond were phone called. Each questionnaire consisted of the 12 I-GERQ-R items along with additional questions regarding family history, feeding habits, sleep, medical treatments, growth, hospitalizations and parental perception of the child's health. A score $\geq 1$ on the first item (presence of regurgitations) combined with a I-GERQ-R score $<16$ indicated GER; with an I-GERQ-R score $\geq 16$ indicated GERD [15].

The hospital ethics committee approved the study and all parents provided informed consent. The study was also approved by the French Advisory Committee on Information Processing in Material Research in the Field of Health (agreement\#2014/165).

Statistical analysis

Numerical data were expressed as median (interquartile range) or as mean \pm standard deviation according to their parametric distribution. Qualitative data were expressed as a number (percentage). The prevalence of GERD was assessed at each questionnaire by the proportion of children with a GER or GERD score according to the total number of children who answered the questionnaires. Missing data were not included to measure prevalence. Clinical factors associated with the risk of GER or GERD were analyzed using chi-squared tests in univariate analysis and a multivariate logistic regression. $P$ values < 0.05 were considered statistically significant. All analyses were performed using SAS software, version 9.1 (SAS Institute, Cary, NC).

\section{Results}

347 living neonates were born during the inclusion period of two months, 157 were included (83 boys, $53 \%)$. The cohort included two pairs of twins, one homozygous, and the other heterozygous. Among the 190 neonates not participating to this study, $115(60 \%)$ did not participate because of parental refusal and 75 (39\%) were excluded mainly for preterm birth (Fig. 1). $89 \%$ of the participants completed the questionnaire at 1 month, $88 \%$ at 3 months, $81 \%$ at 6 months and 10 months and $82 \%$ at 12 months. Only 10 parents did not answer any of the questionnaires. They were excluded from the analysis. Most questionnaires were completed by the mother. The median (range) age of responders was 25.2 years (20.3-43.8), vs. 28.7 years (22.4-37.4) for non-responders. Parity was similar too among groups.

The regurgitation incidence during the first month of life was $72.3 \%$ ( $-95 \% \mathrm{Cl}[64.9-79.7]-)$. The percentage of infants regurgitating at least once a day decreased thereafter: $69 \%, 56 \%, 18 \%$, and $13 \%$ at $3,6,10$, and 12 months, respectively. Few infants regurgitated more than 6 times a day ( $7 \%$ at 1 month and $6 \%$ at 3 and 6 months of age, and almost none thereafter) (Fig. 2).

The progression of physiological GER and GERD were markedly different. Whereas physiological GER peaked at 3 months of age (59.4\%), GERD peaked at 1 month of age (19\%) (Fig. 3). The prevalence of GERD thereafter dropped from $9 \%$ at 3 months to $2 \%$ at 12 months of age. We also noticed a favorable outcome for GERD: of the eleven cases with persistently elevated GERD scores, 7 resolved without 
treatment and 4 with prokinetic agents and/or antacids. Furthermore, in 3 of 6 infants who presented GERD at only one time point ( 4 infants at 3 months and 2 infants at 10 months), elevated scores were associated with concurrent diseases the day before completion of the questionnaire: bronchiolitis $(n=1)$, hives $(n=1)$ and fever $(n=1)$.

Two risk factors were identified for GER and GERD at one month of age: family history of GER (OR: 2.995\% $\mathrm{Cl}[1.2-7.1]$ and OR: $4.8-95 \% \mathrm{Cl}[1.6-14.4]$ - respectively) and exposure to paternal smoking (Table 1). At 3 months, family history of GER was significantly associated with the risk of GER in the infant (-OR (95\%Cl): 31[3.6-265.1]-) (Table 2).

The rate of exclusive breastfeeding was $49 \%$ at 1 month, $31 \%$ at 3 months and 9 at 10 months of age. At 1 month the rate of breastfeeding was $33.3 \%, 56.0 \%$ and $51.8 \%$ in the No GER, GER and GERD, groups respectively (Table 2 ).

The main treatment of GER was dietary change: overall, during the first year of life, $14 \%$ of infants, on average, were given a thickening agent; $5 \%$ were treated with a pharmacological agent (prokinetic, antacid, and/or PPI). The number of treated infants peaked at 3 months, with $22 \%$ of infants receiving a thickening agent and $11 \%$, pharmacological therapy. Yet only $21 \%$ of all treatments were relevant. $9 \%$ infants without GER were treated at 3 months of age.

The median (range) age of introduction of solid food was 6.5 (5.2-9.3) months of age. There was no significant difference regarding the timing of introduction of solids in infants with or without GER.

\section{Discussion}

In this prospective cohort study, we aimed at determining the prevalence of GER and GERD in infants followed longitudinally from birth to 12 months of age. Almost half of the infants aged less than 12 months experienced at least one daily episode of regurgitation, mainly in the first three months of life. The prevalence of physiological GER peaked at age 3 months, $60 \%$ infants, while GERD peaked at age 1 month; almost $20 \%$. The risk factors for GER and GERD were family history of GER, and exposure to passive smoking.

More than two-third of infants regurgitated daily at one month and this figure gradually declined until 12 months of age. Although the timeframes were somewhat different, the rates were similar to those published by Nelson et al. In a cross-sectional survey from pediatric practice, half of the 948 infants regurgitated at least once a day between 0 and 3 months, peaking at $67 \%$ at 4 months, and decreasing thereafter to $61 \%$ at 6 months and $21 \%$ at 7 months of age [5]. Thus, the prevalence of regurgitation remained unchanged over the years. Our results are also similar to those published elsewhere. In the first prospective longitudinal study including 4672 infants (2002), "visible" regurgitation ("spilling") peaked at 3-4 months of age (41\% of infants), and decreased to $5 \%$ at age $13-14$ months [6]. In a survey of pediatricians in 2005 , the regurgitations were the most common gastrointestinal "symptom" in infants aged $0-6$ months, affecting $23.1 \%$ infants [16]. The average prevalence of regurgitation over the first 
2 years of life was $12 \%$ and common before 5 months of age, according to Campanozzi's evaluation using Rome II criteria and the validated I-GERQ score [7]. Using I-GERQ, Salvatore's performed a crosssectional study of 200 infants from 0.5 to 12 months of age and found an average of $45 \%$ of healthy infants regurgitating daily [17]. A prospective study in 2010 of 128 infants in Michigan, USA, using an IGERQ-R score, determined the prevalence of regurgitations at least once a day to be $82 \%, 77 \%, 83 \%, 67 \%$ at $1,2,4$, and 6 months, respectively, with GERD in $25.5 \%, 12.5 \%, 8.0 \%$, and $2.9 \%$ of infants, respectively [8].

In 2012 a French study included 10394 patients, aged $0-17$ years, seen by the family physicians (general practitioners and paediatricians). For patients presenting with GER symptoms, a 24-item questionnaire was completed by the physician. Martigne et al. estimated that $24.4 \%$ of infant (ages 0-23 months) had symptoms of GER. Among infants, $81 \%$ had GER symptoms at least twice a day. The high prevalence of regurgitation may be explained by the enrollment of children who were seen in the physician's office. In addition, the diagnosis was established by the physician and not on parental reports of their children's symptoms [4].

In the present study, environmental tobacco smoke exposure was associated with an increased risk of GER and GERD at 1 month of age. Tobacco smoke is known to induce the relaxation of the lower esophageal sphincter [18]. Two studies had already identified tobacco exposure as a risk factor for GER [18] and GERD [14], although other studies did not report that association [6, 7, 17]. The fact that paternal smoking was significantly more frequent than maternal smoking may be related to a sociocultural context wherein more men than women smoked, mothers may be more sensitive than father to avoid smoking in the baby's environment.

Gender was not correlated with an increased risk of GER or GERD, such as found in previous pediatric study in which the occurrence of pathological $\mathrm{pH}$ monitoring data was equally frequent in boys and girls [19]. A systematic review that included 31 studies of risk factors associated with GERD (only one pediatric study) published in 2014, showed that male sex was not associated with GERD [20].

In the current study, a family history of GER in the first- or second-degree relatives was a strong risk factor for physiological GER and GERD in the first 3 months of age. Four studies reported an association between having GERD symptoms and having a genetically related family member with gastrointestinal symptoms [21-23].

We did not find a statistically significant relationship between breastfeeding and the risk of GER nor GERD, consistent with other studies showing no protective benefit of breastfeeding on GER/GERD [6, 8, 14]. Nonetheless, Heacock et al. suggested that episodes of reflux were shorter in breastfed infants [25]. In Campanozzi's cohort, breastfeeding reduced the frequency of regurgitations as compared to formula feeding [7].

Management options for physiological GER include lifestyle changes [7] (feeding and positional modifications), parental education, reassurance and anticipatory guidance [2]. Providing parental 
education and support as part of the treatment of GERD in association with pharmacologic treatment [3]. The use of alginates may slightly improve visible regurgitation/vomiting as signs and symptoms of GER [3]. Severe GERD may be treated with acid suppressors especially in older infants $[2,26]$. The use of PPIs as first-line treatment of reflux-related erosive esophagitis in infants is recommended [3]. The use of histamine receptor antagonists is recommended if PPIs are contra-indicated or not available [3].

In our cohort, family physicians prescribed dietary manipulation (addition of a thickening agent to formula) to $22 \%$ of infant at 3 months of age. The prescription of pharmacological consisted mainly of antacids, prokinetics, and PPI peaking at $10 \%, 6 \%$ and $3 \%$ respectively, at 3 months of age. We found an overprescribing of pharmacological treatments in infants with GER: nearly $80 \%$ of the prescriptions were unjustified, approximately $1 \%$ of the cohort received PPIs at any time point. Prescription of PPIs has expanded in the pediatric population $[9,11]$. De Bruyne et al. demonstrated an increase in acidsuppressant prescriptions among Belgian pediatricians including PPIs between 1997 and 2009 [10]. In a retrospective analysis of PPI prescribing patterns for newborns and infants, the authors estimated that prescriptions had more than doubled from 2004 to 2008 in United States [12]. Although PPIs are generally highly effective for treating erosive disease [27], they are not effective in reducing GERD symptoms in infants as demonstrated in a systematic review [28]. Moreover, the gastric contents of the milk-fed infants are non-acidic during a large part of the day, obviating the need for suppression of gastric acid secretion. Adverse effects of PPIs are known such as an increase risk of infections: necrostizing enterocolitis, pneumonia, upper respiratory tract infection, urinary tract infection, and Clostridium difficile infections [3]. PPI increase the risk of bone fracture, dementia, myocardial infarction, renal disease [3], vitamin B12 deficiency and hypomagnesaemia [11]. Of notice, in our cohort, the symptoms of GER and GERD largely resolved over time. The use of PPIs in this population is therefore questionable.

A major strength of our study was its prospective design. Furthermore, we included a relatively long follow-up (one year), as opposed to some studies that ended after 6 months. The population was based on infants born at term and healthy, remaining without serious complications for the first 3 months of life. With an almost $90 \%$ rate of return, our study results can therefore be generalized to any well-baby visit. In addition, comparing our results to those from an academic rural population in the USA showed little difference to our experience in a small urban community in France, thus rendering our findings extrapolative to other populations [8].

Nonetheless, there are several limitations to this study. First, we used the I-GERQ-R questionnaire as a surrogate for accurate gastroesophageal reflux diagnosis. This score was validated in many languages including French and was developed to distinguish GER from GERD on clinical criteria. However, items such as the frequency of crying and other infant behaviors can be influenced by underlying diseases and falsely increase the total score. Van Howe and Storms suggested that a high score in the first months of life may reflect colic-associated symptoms and that GERD should not be considered a likely diagnosis until 3 months of age [8]. While sensitive as a screening tool, the I-GERQ-R score should probably be complemented by other, albeit more invasive, testing to ensure a proper diagnosis of GERD before prescribing pharmacologic therapy [29]. The second limitation to our study was that participating 
mothers were somewhat younger than the non-participants mothers. Nonetheless, the number of previous children was the same between the two groups. Third, we did not ask sufficient questions to evaluate the socioeconomic status. This potential selection bias may have affected risk factors like environmental tobacco smoke exposure. Lastly, the sample size was insufficient to investigate factors associated with the persistence of GER at older ages where the prevalence of GERD was low.

\section{Conclusion}

In conclusion, in this prospective cohort study, the prevalence of GER was high in infants aged less than one year but most cases resolved spontaneously with time as infants get older. The best therapeutic options thereby remain parental reassurance and education regarding symptoms, warning signs, and a generally favorable prognosis. We identified two risk factors, one of which is preventable: environmental tobacco smoke exposure and family history of GER. Pharmacologic therapies are justified only in the case of ascertained GERD, keeping in mind that PPIs have not been proven effective in infants with GER. While useful as a clinical screening tool, I-GERQ-R does not replace other, albeit more invasive, investigations to confirm the diagnosis in selected cases.

\section{Abbreviations}

GER: gastroesophageal reflux, GERD: gastroesophageal reflux disease, I-GERQ-R: Infant Gastroesophageal Reflux Questionnaire Revised, PPI: proton pump inhibitor

\section{Declarations}

Ethics approval and consent to participate: The clinical ethics committee of the Besançon Teaching Hospital approved the study ( and all parents provided informed consent. The study was also approved by the French Advisory Committee on Information Processing in Material Research in the Field of Health (agreement\#2014/165). The informed consent obtained from study participants was written.

Consent for publication: Not applicable.

Availability of data and materials: The datasets used and/or analysed during the current study are available from the corresponding author on reasonable request.

Competing interests: The authors declare that they have no competing interests.

Funding: Not applicable.

Authors' contribution: PJ contributed to study design and implementation, design and implementation of the statistical analysis, interpretation of results, and drafting and review of the manuscript. MCC contributed to design and implementation of the study, follow-up of patients, data collection, drafting and review of the manuscript. All authors have read and approved the manuscript. 
Acknowledgements: Not applicable.

\section{References}

1. Vandenplas Y, Rudolph CD, Di Lorenzo C, Hassall E, Liptak G, Mazur L, et al. Pediatric gastroesophageal reflux clinical practice guidelines: joint recommendations of the North American Society for Pediatric Gastroenterology, Hepatology, and Nutrition (NASPGHAN) and the European Society for Pediatric Gastroenterology, Hepatology, and Nutrition (ESPGHAN). J Pediatr Gastroenterol Nutr. oct 2009;49(4):498-

2. Gottrand F. [Gastroesophageal reflux in childhood]. Arch Pediatr. 2006 Jul;13(7):1076-9.

3. Rosen R, Vandenplas Y, Singendonk M, Cabana M, DiLorenzo C, Gottrand F, et al. Pediatric Gastroesophageal Reflux Clinical Practice Guidelines: Joint Recommendations of the North American Society for Pediatric Gastroenterology, Hepatology, and Nutrition and the European Society for Pediatric Gastroenterology, Hepatology, and Nutrition. Journal of Pediatric Gastroenterology and Nutrition [Internet]. 2018 Mar;66(3):516-54.

4. Martigne L, Seguy D, Pellegrini N, Orlikowski D, Cuisset J-M, Carpentier A, et al. Efficacy and tolerance of gastrostomy feeding in Duchenne muscular dystrophy. Clin Nutr. 2010 Feb;29(1):60-4.

5. Nelson SP, Chen EH, Syniar GM, Christoffel KK. Prevalence of symptoms of gastroesophageal reflux during infancy. A pediatric practice-based survey. Pediatric Practice Research Group. Arch Pediatr Adolesc Med. 1997 Jun;151(6):569-72.

6. Martin AJ, Pratt N, Kennedy JD, Ryan P, Ruffin RE, Miles H, et al. Natural history and familial relationships of infant spilling to 9 years of age. 2002 Jun;109(6):1061-7.

7. Campanozzi A, Boccia G, Pensabene L, Panetta F, Marseglia A, Strisciuglio P, et al. Prevalence and natural history of gastroesophageal reflux: pediatric prospective survey. 2009 Mar;123(3):779-83.

8. Van Howe RS, Storms MR. Gastroesophageal reflux symptoms in infants in a rural population: longitudinal data over the first six months. BMC Pediatr. 2010 Feb 11;10:7.

9. Barron JJ, Tan H, Spalding J, Bakst AW, Singer J. Proton pump inhibitor utilization patterns in infants. J Pediatr Gastroenterol Nutr. oct 2007;45(4):421-

10. De Bruyne P, Christiaens T, Vander Stichele R, Van Winckel M. Changes in prescription patterns of acid-suppressant medications by Belgian pediatricians: analysis of the national database, [19972009]. J Pediatr Gastroenterol Nutr. 2014 Feb;58(2):220-5

11. De Bruyne P, Ito S. Toxicity of long-term use of proton pump inhibitors in children. Arch Dis Child. 2018 Jan;103(1):78-82.

12. Illueca $\mathrm{M}$, Alemayehu $B$, Shoetan $N$, Yang $H$. Proton pump inhibitor prescribing patterns in newborns and infants. J Pediatr Pharmacol Ther. 2014 Dec;19(4):283-7. 
13. Orenstein SR, Cohn JF, Shalaby TM, Kartan R. Reliability and validity of an infant gastroesophageal reflux questionnaire. Clin Pediatr (Phila). 1993 Aug;32(8):472-84.

14. Orenstein SR, Shalaby TM, Cohn JF. Reflux symptoms in 100 normal infants: diagnostic validity of the infant gastroesophageal reflux questionnaire. Clin Pediatr (Phila). 1996 Dec;35(12):607-14.

15. Kleinman L, Rothman M, Strauss R, Orenstein SR, Nelson S, Vandenplas $Y$, et al. The infant gastroesophageal reflux questionnaire revised: development and validation as an evaluative instrument. Clin Gastroenterol Hepatol. 2006 May;4(5):588-96.

16. Iacono G, Merolla R, D'Amico D, Bonci E, Cavataio F, Di Prima L, et al. Gastrointestinal symptoms in infancy: a population-based prospective study. Dig Liver Dis. 2005 Jun;37(6):432-8.

17. Salvatore S, Hauser B, Vandemaele K, Novario R, Vandenplas Y. Gastroesophageal reflux disease in infants: how much is predictable with questionnaires, pH-metry, endoscopy and histology? J Pediatr Gastroenterol Nutr. 2005 Feb;40(2):210-5.

18. Alaswad B, Toubas PL, Grunow JE. Environmental tobacco smoke exposure and gastroesophageal reflux in infants with apparent life-threatening events. J Okla State Med Assoc. 1996 Jul;89(7):2337.

19. Peeters S, Vandenplas Y. Sex ratio of gastroesophageal reflux in infancy. J Pediatr Gastroenterol Nutr. 1991 Oct;13(3):314.

20. El-Serag HB, Sweet S, Winchester CC, Dent J. Update on the epidemiology of gastro-oesophageal reflux disease: a systematic review. Gut. 2014 Jun;63(6):871-80.

21. Locke GR, Talley NJ, Fett SL, Zinsmeister AR, Melton LJ. Risk factors associated with symptoms of gastroesophageal reflux. Am J Med. 1999 Jun;106(6):642-9.

22. Mohammed I, Cherkas LF, Riley SA, Spector TD, Trudgill NJ. Genetic influences in gastro-oesophageal reflux disease: a twin study. Gut. 2003 Aug;52(8):1085-9.

23. He J, Ma X, Zhao Y, Wang R, Yan X, Yan H, et al. A population-based survey of the epidemiology of symptom-defined gastroesophageal reflux disease: the Systematic Investigation of Gastrointestinal Diseases in China. BMC Gastroenterol. 2010 Aug 15;10:94.

24. Zheng Z, Nordenstedt H, Pedersen NL, Lagergren J, Ye W. Lifestyle factors and risk for symptomatic gastroesophageal reflux in monozygotic twins. Gastroenterology. 2007 Jan;132(1):87-95.

25. Heacock HJ, Jeffery HE, Baker JL, Page M. Influence of breast versus formula milk on physiological gastroesophageal reflux in healthy, newborn infants. J Pediatr Gastroenterol Nutr. 1992 Jan;14(1):41-6.

26. Hassall E. Over-prescription of acid-suppressing medications in infants: how it came about, why it's wrong, and what to do about it. J Pediatr. 2012 Feb;160(2):193-8.

27. Joret-Descout P, Dauger S, Bellaiche M, Bourdon O, Prot-Labarthe S. Guidelines for proton pump inhibitor prescriptions in paediatric intensive care unit. Int J Clin Pharm. 2017 Feb;39(1):181-6.

28. Van der Pol RJ, Smits MJ, van Wijk MP, Omari TI, Tabbers MM, Benninga MA. Efficacy of protonpump inhibitors in children with gastroesophageal reflux disease: a systematic review. Pediatrics. 
2011 May;127(5):925-35.

29. Orenstein SR. Symptoms and reflux in infants: Infant Gastroesophageal Reflux Questionnaire Revised (I-GERQ-R)-utility for symptom tracking and diagnosis. Curr Gastroenterol Rep. 2010 Dec;12(6):431-6.

\section{Tables}

Table 1. Multivariate analysis of the risk factors for GER and GERD at one month of age

$(N=141)$

\begin{tabular}{|c|c|c|c|c|c|c|}
\hline & No GER & GER & GERD & $p$ & OR $[95 \% \mathrm{Cl}]$ & OR[ $95 \% \mathrm{Cl}]$ \\
\hline & $\begin{array}{l}\mathrm{N}=39 \\
\mathrm{n}(\%)\end{array}$ & $\begin{array}{l}\mathrm{N}=75 \\
\mathrm{n}(\%)\end{array}$ & $\begin{array}{l}\mathrm{N}=27 \\
\mathrm{n}(\%)\end{array}$ & & $\begin{array}{l}\text { GER vs No } \\
\text { GER }\end{array}$ & $\begin{array}{l}\text { GERD vs No } \\
\text { GER }\end{array}$ \\
\hline $\begin{array}{l}\text { Family history of } \\
\text { GER }\end{array}$ & $8(20.5)$ & $\begin{array}{l}32 \\
(42.7)\end{array}$ & $\begin{array}{l}15 \\
(55.6)\end{array}$ & $\underset{*}{0.01}$ & $\begin{array}{l}2.9 \\
{[1.2-7.1]}\end{array}$ & $\begin{array}{l}4.8 \\
{[1.6-14.4]}\end{array}$ \\
\hline Sex-male & $\begin{array}{l}19 \\
(48.7)\end{array}$ & $\begin{array}{l}43 \\
(57.3)\end{array}$ & $\begin{array}{l}15 \\
(55.6)\end{array}$ & 0.68 & $\begin{array}{l}1.4 \\
{[0.6-3.1]}\end{array}$ & $\begin{array}{l}1.3 \\
{[0.5-3.5]}\end{array}$ \\
\hline $\begin{array}{l}\text { Exclusive } \\
\text { breastfeeding }\end{array}$ & $\begin{array}{l}13 \\
(33.3)\end{array}$ & $\begin{array}{l}42 \\
(56.0)\end{array}$ & $\begin{array}{l}14 \\
(51.8)\end{array}$ & 0.09 & $\begin{array}{l}2.5 \\
{[1.1-5.7]}\end{array}$ & $\begin{array}{l}2.1 \\
{[0.8-5.9]}\end{array}$ \\
\hline Paternal smoking & $\begin{array}{l}15 \\
(38.5)\end{array}$ & $\begin{array}{l}21 \\
(28.0)\end{array}$ & $\begin{array}{l}15 \\
(55.6)\end{array}$ & $0.03^{\star}$ & $\begin{array}{l}0.6 \\
{[0.2-1.4]}\end{array}$ & $\begin{array}{l}2.0 \\
{[0.7-5.4]}\end{array}$ \\
\hline Maternal smoking & $6(15.4)$ & $\begin{array}{l}13 \\
(17.3)\end{array}$ & $6(22.2)$ & 0.76 & $\begin{array}{l}1.1 \\
{[0.4-3.3]}\end{array}$ & $\begin{array}{l}1.6 \\
{[0.4-5.5]}\end{array}$ \\
\hline
\end{tabular}

GER, gastroesophageal reflux. 
GERD, gastroesophageal reflux disease.

Table 2. Multivariate analysis of the risk factors GER and GERD at three months of age $(N=138)$.

\begin{tabular}{|c|c|c|c|c|c|c|}
\hline & No GER & GER & GERD & $p$ & OR [95\%Cl] & OR $[95 \% \mathrm{Cl}]$ \\
\hline & $\begin{array}{l}\mathrm{N}=43 \\
\mathrm{n}(\%)\end{array}$ & $\begin{array}{l}\mathrm{N}=82 \\
\mathrm{n}(\%)\end{array}$ & $\begin{array}{l}\mathrm{N}=13 \\
\mathrm{n}(\%)\end{array}$ & & $\begin{array}{l}\text { GER vs No } \\
\text { GER }\end{array}$ & $\begin{array}{l}\text { GERD vs No } \\
\text { GER }\end{array}$ \\
\hline $\begin{array}{l}\text { Family history of } \\
\text { GER }\end{array}$ & $\begin{array}{l}12 \\
(27.9)\end{array}$ & $\begin{array}{l}26 \\
(31.7)\end{array}$ & $\begin{array}{l}12 \\
(92.3)\end{array}$ & $<0.0001^{*}$ & $\begin{array}{l}1.2 \\
{[0.5-2.7]}\end{array}$ & $\begin{array}{l}31 \\
{[3.6-265.1]}\end{array}$ \\
\hline Sex-male & $\begin{array}{l}20 \\
(46.5)\end{array}$ & $\begin{array}{l}44 \\
(53.7)\end{array}$ & $\begin{array}{l}10 \\
(76.9)\end{array}$ & 0.16 & $\begin{array}{l}1.33 \\
{[0.6-2.8]}\end{array}$ & $\begin{array}{l}3.83 \\
{[0.9-15.9]}\end{array}$ \\
\hline $\begin{array}{l}\text { Exclusive } \\
\text { breastfeeding }\end{array}$ & $11(25.6)$ & $\begin{array}{l}27 \\
(32.9)\end{array}$ & $\begin{array}{l}5 \\
(38.5)\end{array}$ & 0.6 & $\begin{array}{l}1.43 \\
{[0.6-3.3]}\end{array}$ & $\begin{array}{l}1.82 \\
{[0.5-6.7]}\end{array}$ \\
\hline Paternal smoking & $\begin{array}{l}18 \\
(41.9)\end{array}$ & $\begin{array}{l}24 \\
(29.3)\end{array}$ & $\begin{array}{l}5 \\
(38.5)\end{array}$ & 0.3 & $\begin{array}{l}0.57 \\
{[0.3-1.2]}\end{array}$ & $\begin{array}{l}0.87 \\
{[0.2-3.1]}\end{array}$ \\
\hline Maternal smoking & $9(20.1)$ & $\begin{array}{l}12 \\
(14.6)\end{array}$ & $\begin{array}{l}2 \\
(15.4)\end{array}$ & 0.7 & $\begin{array}{l}0.65 \\
{[0.2-1.7]}\end{array}$ & $\begin{array}{l}0.69 \\
{[0.1-3.7]}\end{array}$ \\
\hline
\end{tabular}

GER, gastroesophageal reflux.

GERD, gastroesophageal reflux disease.

\section{Figures}




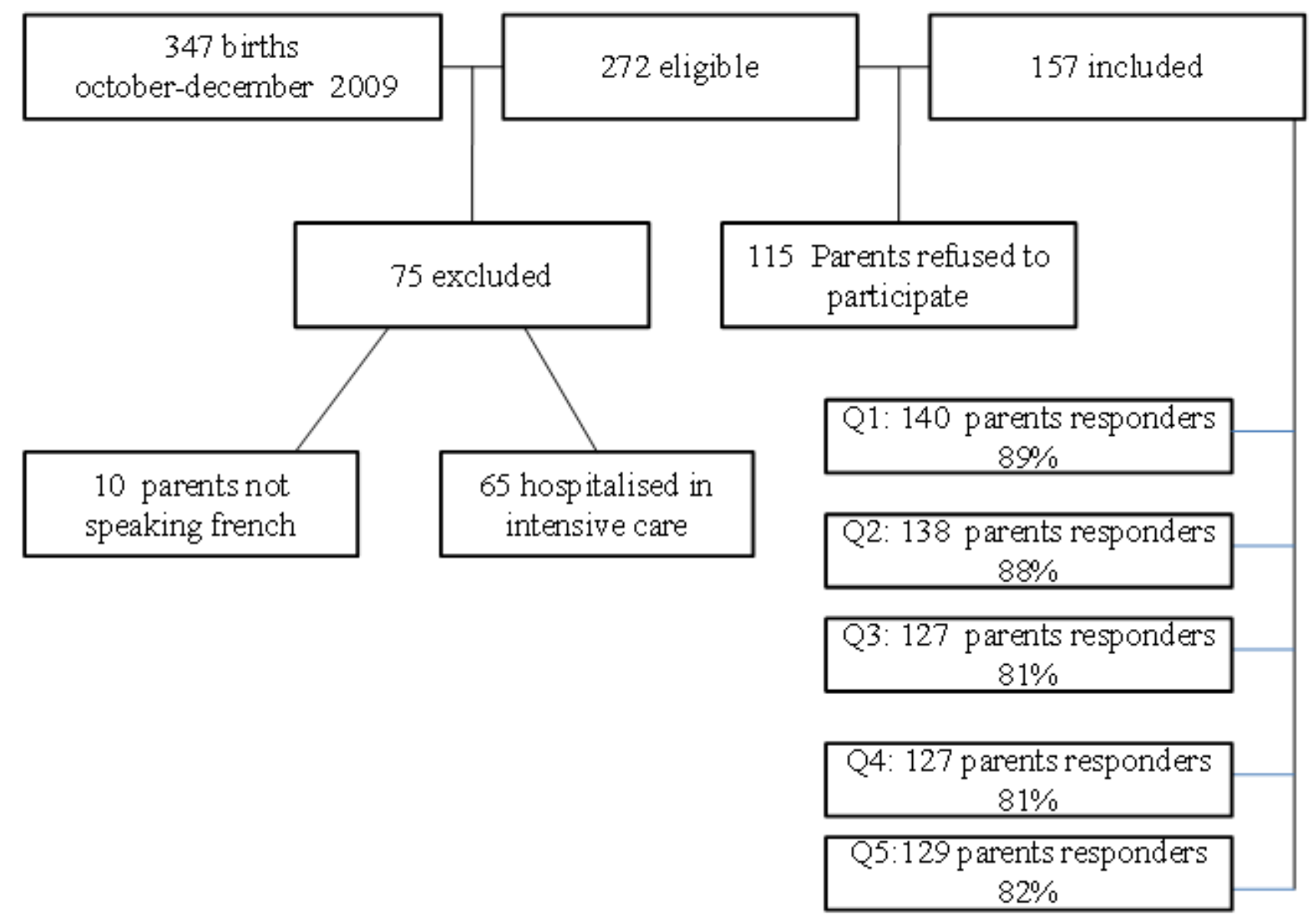

Figure 1

Study flowchart of patients selection and follow-up. 


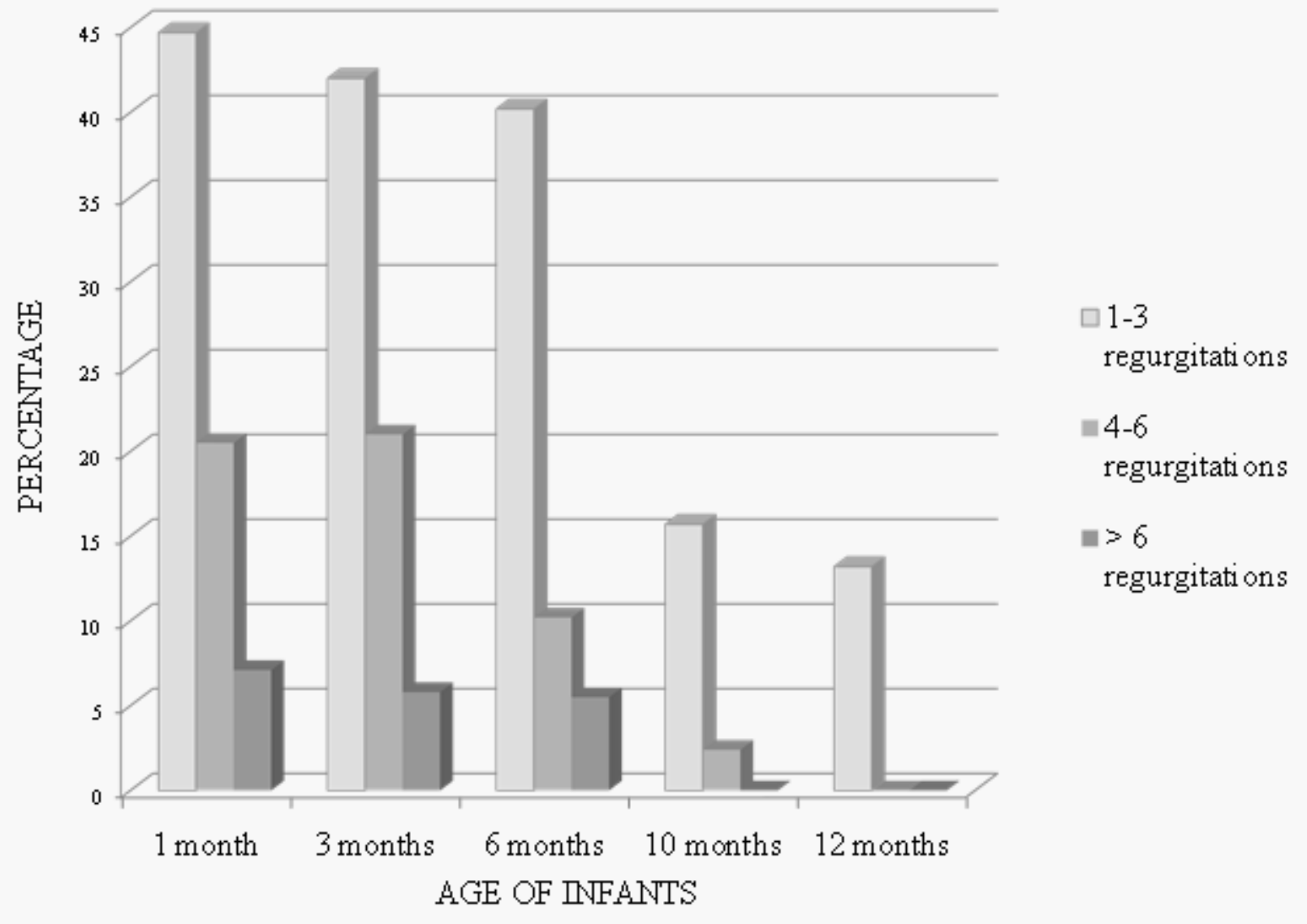

Figure 2

Incidence of daily regurgitation between one and twelve months of age. 


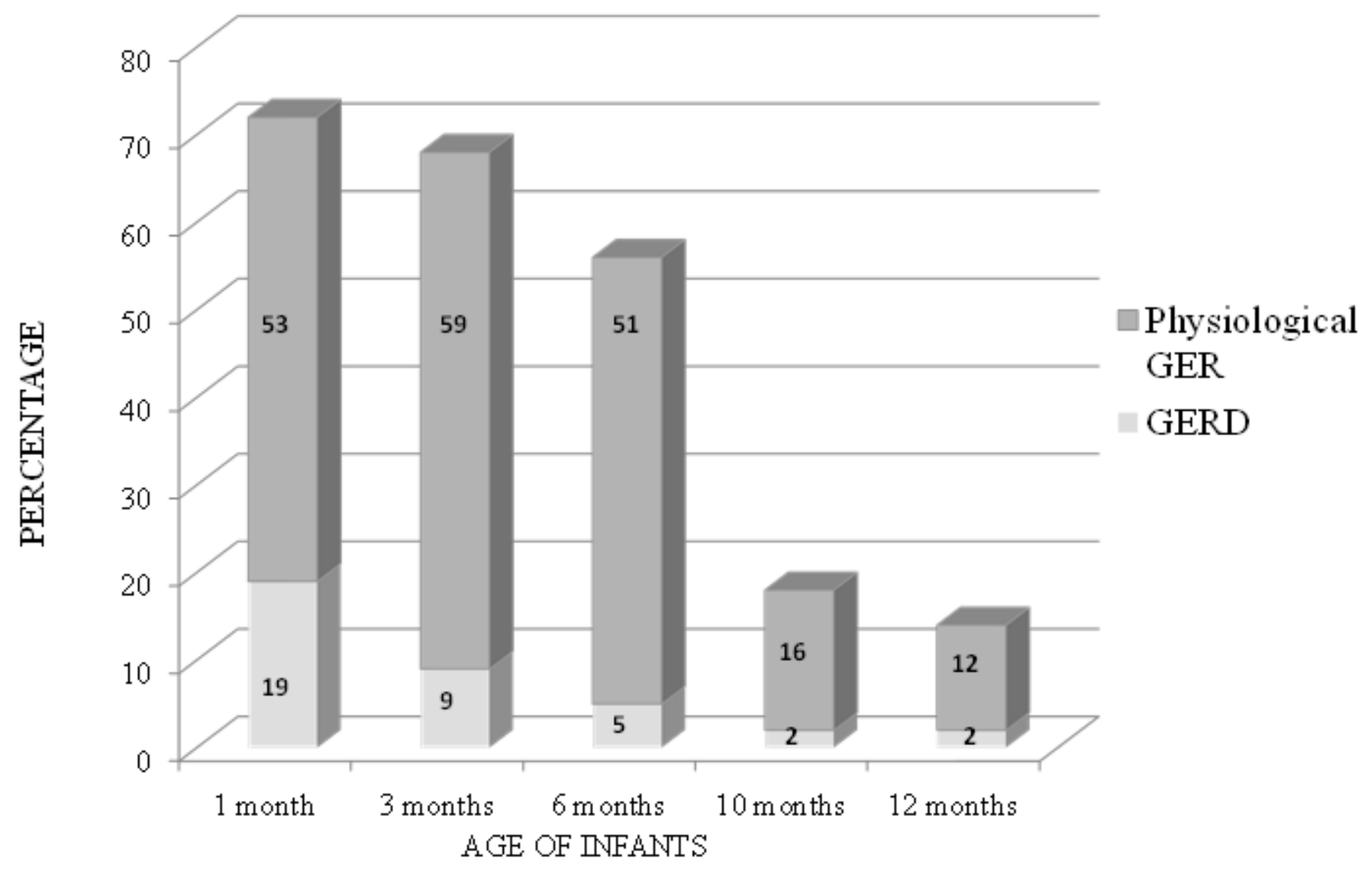

Figure 3

Incidence of GER and GERD between one and twelve months of age.

\section{Supplementary Files}

This is a list of supplementary files associated with this preprint. Click to download.

- STROBEchecklistdoc.doc 